\title{
Sensitivity Analysis of Key Factors Influencing Carbon Prices under the EU ETS
}

\author{
Chao Jiang*, Yunliang Yue \\ School of Information Engineering, Yangzhou University, Yangzhou 225127, China
}

Received: 31 December 2019

Accepted: 1 December 2020

\begin{abstract}
The carbon market has become a major mechanism for global carbon emission reduction. However, the actual operation of the carbon market does not meet the expectation due to the drastic fluctuation of carbon prices. It is of great importance for regulators to fully understand the dynamic operation of the carbon market. This paper employs the carbon market dynamic assessment model to analyze key factors including emission reduction targets and power loads, which influence carbon prices under the European Union Emissions Trading System (EU ETS). The feasibility of the model is verified by simulating the carbon price crisis of the second stage of EU ETS. The simulation results specify that the total emissions are more susceptible to changes of power loads than emission reduction targets, which explains why the European Commission could do little to stabilize the carbon market when facing the disturbances of the global financial crisis and the European crisis. In addition, the threshold carbon price has a great important influence on emission reductions, which is of great importance for regulators to improve the market efficiency. Furthermore, according to the transfer rate from carbon prices to electricity prices, governmental subsidies could be needed to ensure the stability of the power grid.
\end{abstract}

Keywords: emission trading, generation company, carbon market dynamic assessment model, sensitivity analysis

\section{Introduction}

The carbon market has become a major mechanism for global carbon emission control $[1,2]$. The theoretical basis of the carbon market is the externalities of environmental pollution and the Coase Theorem. In theory, if the definition of emission right is clear and transaction costs are close to zero, carbon market can achieve optimal resource allocation and reach emission reduction targets with minimum social costs [3, 4].

*e-mail: jiangchao@yzu.edu.cn
However, due to the lack of elasticity of the carbon allowance supply curve, and the fact that allowance demand for regulated companies is greatly affected by the external environment, the drastic fluctuation of carbon prices, especially the extreme carbon prices occur frequently, which is not conducive to capital investment in structural emissions reduction $[5,6]$. Therefore, if carbon market regulators want to achieve reduction targets at a lower social cost, it is necessary to conduct sensitivity analysis of key factors in the emission market.

Whether the carbon market model accurately reflects the impact of parameter changes on the actual carbon market directly leads to the reliability and effectiveness 
of the final sensitivity analysis results. Therefore, the construction of the carbon market model is the key to the sensitivity analysis of the carbon market [7]. There has been considerable research about the existing Emissions Trading System (ETS). The research methods of the carbon market dynamic assessment model mainly include econometric models, computable general equilibrium models (CGE), experimental economic methods, and multi-agent models. Econometric models and CGE can reflect the impact of macro variables on the carbon market, but it is difficult to dynamically simulate the carbon market risk, usually applied to empirical analysis and long-term planning [8, 9]. Experimental economics can accurately simulate the dynamic trajectory of the actual carbon market, but due to the difficulty of occupying a large number of participants for a long time, there are limitations in the scale of repeatability of the experiment [10, 11]. The multi-agent model is a viable solution to analyze the impact of disturbances or control measures at the micro level, as well as assess the operation performance of the carbon market at the macro level [12, 13]. However, uncertainties in the actual market make participants' decision-making more complicated, while multi-agent model mainly adopts regular transactions and determines the transaction volume based on the emission imbalance [14, 15], which is difficult to reflect the decision-making preferences of participants, affecting the accuracy of the sensitivity analysis as a result. Therefore, the behavioral characteristics of participants need to be further considered in the multiagent model.

Carbon emission trading is confirmed to be an effective environment policy to realize emission reduction [16]. In developing countries, such as China, with the implementation of ETS, in order to consider the economic growth or $\mathrm{PM}_{25}$ emissions, improving energy efficiency is one of the most important measures to reduce carbon emissions [17, 18]. The European Union Emissions Trading System (EU ETS) is the world's largest and most influential carbon market [19]. However, under the influence of many internal and external factors, the carbon market price of the second stage (2008-2012) of EU ETS showed a violent oscillation [20,21]. The sensitivity analysis of key factors in EU ETS has implications for regulators to design and improve the carbon market mechanism. According to the rules of EU ETS, this paper constructs a carbon market model, including production simulation of controlled enterprises, carbon trading behavior agents, and carbon market price models. Furthermore, taking the carbon price crisis of the second stage of EU ETS as the research object, combined with specific data, this paper simulates the trend of carbon price to verify the feasibility of the carbon market dynamic assessment model. Finally, the sensitivity analysis of key factors in EU ETS is conducted and discussed to support the decision-making of the regulatory agencies.

\section{Materials and Methods}

\author{
Model Formulation
}

EU ETS covers the power, heat, chemical, cement and other industries. As the electricity industry is the hub of energy production and consumption, emission management is not only related to its own sustainable development, but also affects whether the emission reduction target can be successfully achieved [22]. According to the carbon emission level, about 68\% of carbon emissions come from the energy industry (electricity and heat) based on the 2015 EU ETS carbon emission statistics [23]. With regard to the allowance allocation, nearly $50 \%$ of the allowances in the second phase of EU ETS is allocated to the power industry [24]. As to the enthusiasm of market participants, the power industry is more motivated to participate in the carbon market [25]. In view of the representativeness of the power industry in the carbon market and the availability of its data, this paper attempts to take the European power generation industry as the representative, to simulate the evolution of supply and demand in the carbon market, considering the impact of major disturbances on the supply and demand of electricity.

The framework of the carbon market dynamic assessment model includes the allowance allocation model, the carbon price model, the generation and emission model, and the trading behavior model (as shown in Fig. 1). Firstly, the initial allowances are allocated to generation companies (GenCos) according to the allowance allocation model. And then through the generation and emission model, the amount of power generation and emissions are determined. Based on the emission balance calculated and the current carbon price, the trading volumes are determined by the trading behavior model, and finally the carbon price model simulates the impact of trading behaviors on carbon prices. According to this process, the dynamic trend of carbon market operation under the entire compliance period is simulated.

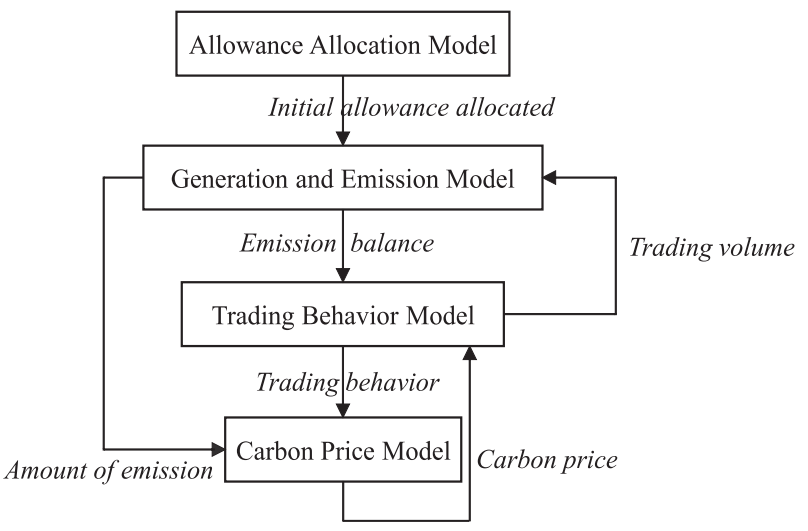

Fig. 1. The framework of the carbon market dynamic assessment model. 


\section{Allowance Allocation Model}

According to the allocation rules of the initial allowance allocation in the second phase of the EU ETS, the initial allowance allocation of the generators adopts the grandfathering method based on historical emissions [26], as shown in equation (1).

$$
q_{i}^{a}=q_{i}^{h} \times \lambda_{i}^{c} \times \lambda_{i}^{a}
$$

Among them, $q_{i}^{a}$ is the initial allowance that is freely obtained for generation company (GenCo) $i, q_{i}^{h}$ is the historical emission level of the GenCo $i, \lambda_{i}^{c}$ is the control coefficient set for supervision, and $\lambda_{i}^{a}$ is the ratio of free allocation.

$$
Q^{a}=\sum_{i=1}^{N^{g}} q_{i}^{a}
$$

In this paper, it is assumed that the GenCos are the only participants in the market, so the total amount of allowances in circulation is the sum of the initial allocation for each GenCos, as shown in equation (2), where $N^{g}$ is the number of GenCos.

\section{Price Model}

This paper uses the demand-price model we've proposed to simulate the impact of carbon market supply and demand on prices [27]. The carbon price of a certain day is determined by the carbon price of the previous day, the short-term supply and demand of allowances, and the long-term supply and demand of allowances, as shown in equation (3).

$$
p_{t}^{e}=p_{t-1}^{e}+\alpha \times \frac{\sum_{i=1}^{N^{8}} q_{i, t-1}^{b}-\sum_{i=1}^{N^{g}} q_{i, t-1}^{s}}{\sum_{i=1}^{N^{g}} q_{i, t-1}^{b}+\sum_{i=1}^{N^{8}} q_{i, t-1}^{s}}+\beta \times \frac{t}{T} \times \frac{\left(E_{t} \times \frac{T}{t}-E_{t}\right)-\left(Q^{a}-E_{t}\right)}{Q^{a}}
$$

Among them, $p_{t}^{e}$ is the carbon price of the day $t$, $q_{i, t-1}^{b}\left(q_{i, t-1}^{s}\right)$ is the allowance purchase amount (or sales amount) of the participant in the day $t$, coefficient $\alpha$ and $\beta$ are the impact of short-term and long-term supply and demand on the price respectively, $T$ is the compliance timing, and $E_{t}$ is the total emissions of all GenCos in the day $t$.

In order to better simulate the impact of supply and demand on carbon prices, this paper uses the actual

Table 1. Values of $\alpha$ and $\beta$ in different years.

\begin{tabular}{|c|c|c|c|c|c|}
\hline & 2008 & 2009 & 2010 & 2011 & 2012 \\
\hline$\alpha$ & 0.1649 & 0.1438 & 0.1229 & 0.1128 & 0.1206 \\
\hline$\beta$ & 3.8572 & 1.1537 & 0.5975 & 2.5106 & 1.1351 \\
\hline
\end{tabular}

price curve of EU ETS to carry out the simulation, and then obtains the transaction results of each participant's behavioral model in this price scenario (purchase and sale amount in each period), and finally gets the value of $\alpha$ and $\beta$ in the price model (as shown in Table 1).

\section{Generation and Emission Model}

The economic dispatch model was used to simulate the power generation. Assuming that power units are quoted based on the marginal power generation $\operatorname{cost} c_{j, t}$, which is combined with the marginal fuel cost $c_{j, t}^{f}$ and marginal emission $\operatorname{cost} c_{j, t}^{e}$ [28], as shown in equation (4).

$$
c_{j, t}=c_{j, t}^{f}+c_{j, t}^{e}=p_{j, t}^{f} \times \lambda_{j}^{f}+p_{t}^{e} \times \lambda_{j}^{e}
$$

Among them, $p_{j, t}^{f}$ is the price of fossil fuel used for the power unit $j$ in the day $t, \lambda_{j}^{f}$ is the energy consumption rate of the power unit $j$, and $\lambda_{j}^{e}$ is the emission rate of the power unit $j$.

The unified price clearing mechanism is adopted, and the load is distributed according to the unit price quoted from low to high. The marginal electricity price is the last bidding price of the unit that meets the balance between supply and demand. The emissions of each GenCos can be calculated based on the clearing electric quantity and emission rates of each power units, as shown in equation (5).

$$
e_{i, t}=\sum_{j=1}^{N_{i}^{u}} \lambda_{j}^{e} \times q_{j, t}
$$

Among them, $e_{i, t}$ is the amount of emissions of GenCo $i$ in the day $t, N_{i}^{u}$ is the number of power units owned by the GenCo, and $q_{j, t}$ is the amount of electricity generated by the power unit $j$ in the day $t$.

\section{Trading Behavior Model}

The carbon trading behavior model is constructed based on the hybrid simulation method proposed in our previous work [29]. Based on the actual participants' transaction results, the statistical rules of key driving factors and trading behaviors are extracted. The behavioral driving factors considered include the longterm price trend, the short-term price volatility, and compliance urgency (as shown in equation (6)), and a behavioral agent model is established based on the joint distribution of transaction behaviors on these characteristic variables. 


$$
\begin{aligned}
& r_{t}^{f}=\frac{\left(E_{t} \times \frac{T}{t}-E_{t}\right)-\left(Q^{a}-E_{t}\right)}{Q^{a}} \times 100 \% \\
& r_{t}^{p}=\frac{p_{t}^{e}-\bar{p}_{t}^{e}}{\bar{p}_{t}^{e}} \times 100 \% \\
& r_{t}^{u}=\frac{q_{i}^{a}+\sum_{d=1}^{t-1}\left(q_{i, d}^{b}-q_{i, d}^{s}\right)-\frac{T}{t-1} \sum_{d=1}^{t-1} e_{i, d}}{\frac{T-(t-1)}{t-1} \sum_{d=1}^{t-1} e_{i, d}} \times 100 \%
\end{aligned}
$$

Among them, $r_{t}^{f}$ reflects the long-term price trend, $r_{t}^{p}$ reflects short-term price trend, $r_{t}^{u}$ comprehensively reflects projected emission imbalance and the distance

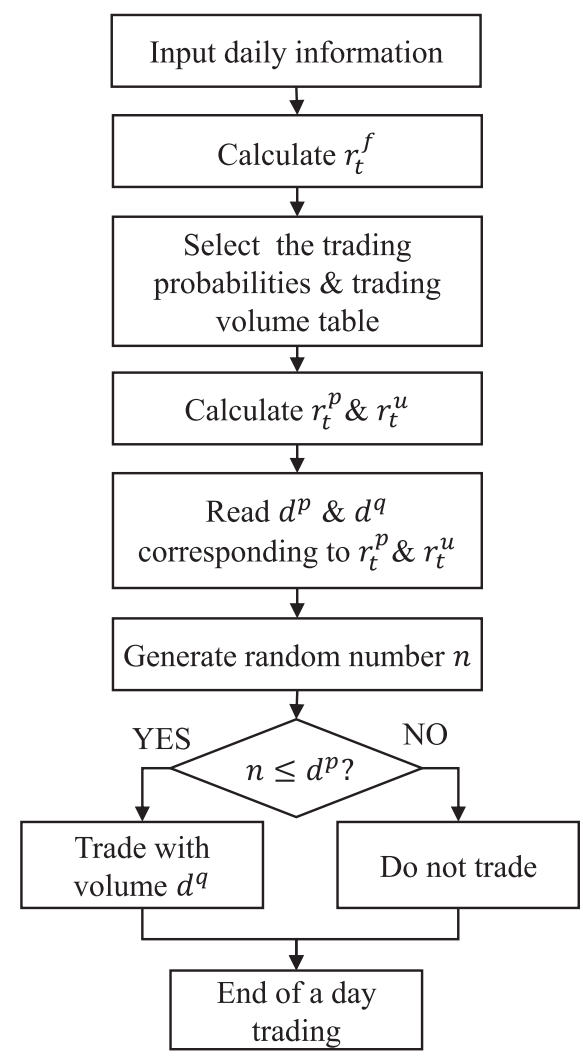

Fig. 2. Decision process of carbon trading behavioral model. between the present timing and the compliance timing, $\bar{p}_{t}^{e}$ is the recent (this takes the last seven days) of carbon prices.

The decision process of the behavioral agent is shown in Fig. 2. During the dynamic simulation process, the behavioral agent collects market information, and calculates the value of the characteristic variable $r_{t}^{f}$, $r_{t}^{p}$ and $r_{t}^{u}$. Random sampling is conducted based on the joint probability distribution of trading decision behaviors and characteristic variables to determine the trading behavior in one day (positive average trading volume indicates purchase and negative value indicates sale). This paper assumes that the behavioral agent is the price-taker in the carbon market, so the trading decision only includes the bidding volume without the bidding price. The detailed model parameters of the behavioral agent can be found in appendix A.

\section{Data Specifications}

\section{Carbon Market Parameters}

The emission reduction target for the second phase of the EU ETS is to reduce the total annual emissions by $6.5 \%$ compared to the total emissions $E^{b}$ in 2005 by 2012. Therefore, based on the actual carbon price curve of 2005, through the simulation the power generation production and the annual emissions of GenCos in 2005 can be calculated as the historical emissions $q_{i}^{h}$ required for the initial allowance allocation in the second phase. According to the second phase emission reduction targets, the emission control factors $\lambda_{i}^{c}$ for each year from 2008 to 2012 were set as $98.7 \%, 97.4 \%, 96.1 \%$, and $93.5 \%$, respectively. According to the actual market rules, the free allocation rate $\lambda_{i}^{a}$ is $90 \%$.

\section{Participant Parameters}

Based on the European power system data from the European Network of Transmission System Operators for Electricity (ENTSO-E), the relevant parameters for GenCos are set, including clean energy units, thermal power units and power loads. On the basis of data in ENTSO-E, the load curve and output of clean

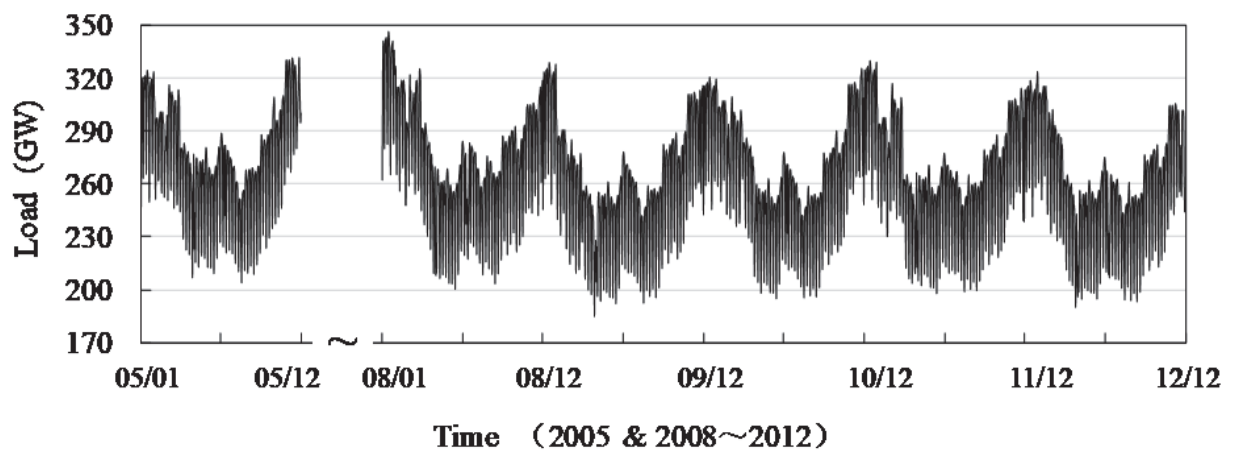

Fig. 3. Yearly load curve in different years. 


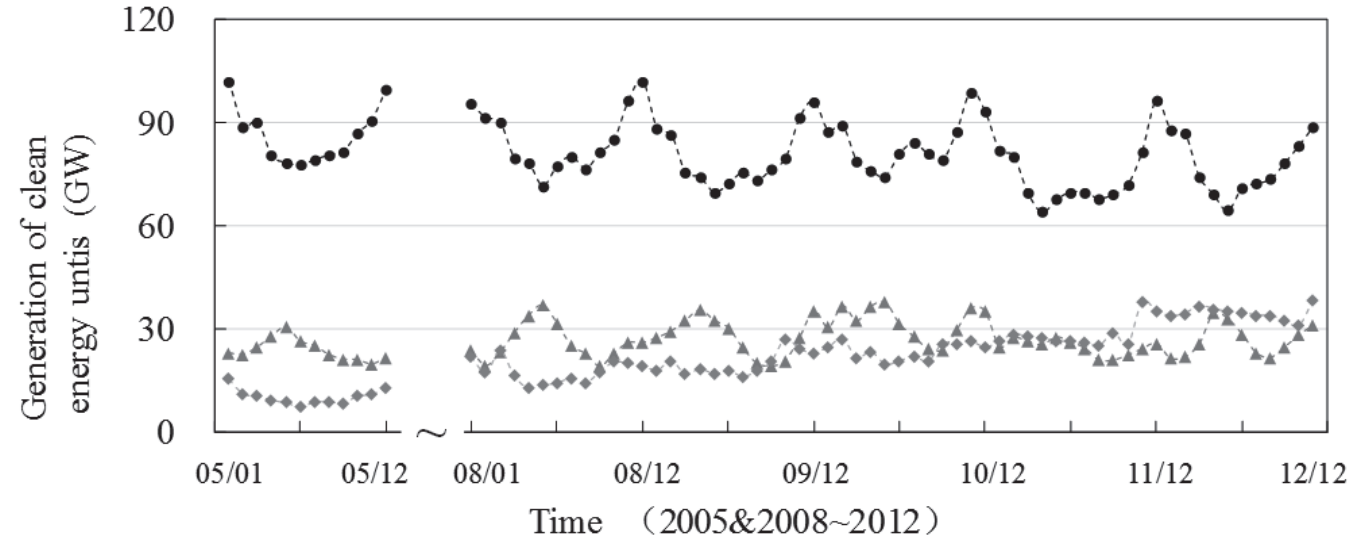

$\cdots$--- Hydropower $\quad \cdots \bullet-$ Nuclear power $\quad \cdots \cdots$ Renewable energy power

Fig. 4. Output of clean energy units in different years.

Table 2. Installed capacities of thermal power units in different years.

\begin{tabular}{|c|c|c|c|c|c|c|}
\hline \multirow{2}{*}{ GenCo } & \multicolumn{6}{|c|}{ Installed capacity (MW) } \\
\cline { 2 - 7 } & 2005 & 2008 & 2009 & 2010 & 2011 & 2012 \\
\hline COAL_A1 & 57594 & 55900 & 49902 & 46135 & 44644 & 46345 \\
\hline COAL_A2 & 62547 & 56846 & 64187 & 57795 & 54235 & 53901 \\
\hline COAL_A3 & 34689 & 42811 & 41901 & 44463 & 53631 & 55788 \\
\hline GAS_B1 & 39493 & 41974 & 40209 & 42586 & 39493 & 42637 \\
\hline GAS_B2 & 42890 & 42683 & 51719 & 53349 & 47977 & 49589 \\
\hline GAS_B3 & 23787 & 32145 & 33762 & 41043 & 47443 & 51325 \\
\hline OIL_C1 & 10696 & 13250 & 12027 & 10647 & 10302 & 11123 \\
\hline OIL_C2 & 11616 & 13474 & 15469 & 13337 & 12516 & 12936 \\
\hline OIL_C3 & 6442 & 10147 & 10098 & 10261 & 12376 & 13389 \\
\hline
\end{tabular}

Table 3. Energy consumption rates and emission rates of thermal power units.

\begin{tabular}{|c|c|c|}
\hline GenCo & Fuel consumption rate & $\begin{array}{c}\text { Emission rate } \\
(\mathrm{g} / \mathrm{kWh})\end{array}$ \\
\hline COAL_A1 & $415(\mathrm{~g} / \mathrm{kWh})$ & 1.225 \\
\hline COAL_A2 & $346(\mathrm{~g} / \mathrm{kWh})$ & 1.021 \\
\hline COAL_A3 & $335(\mathrm{~g} / \mathrm{kWh})$ & 0.987 \\
\hline GAS_B1 & $6462(\mathrm{Btu} / \mathrm{kWh})$ & 0.383 \\
\hline GAS_B2 & $5955(\mathrm{Btu} / \mathrm{kWh})$ & 0.353 \\
\hline GAS_B3 & $5687(\mathrm{Btu} / \mathrm{kWh})$ & 0.337 \\
\hline OIL_C1 & $7006(\mathrm{Btu} / \mathrm{kWh})$ & 0.572 \\
\hline OIL_C2 & $6094(\mathrm{Btu} / \mathrm{kWh})$ & 0.497 \\
\hline OIL_C3 & $5976(\mathrm{Btu} / \mathrm{kWh})$ & 0.488 \\
\hline
\end{tabular}

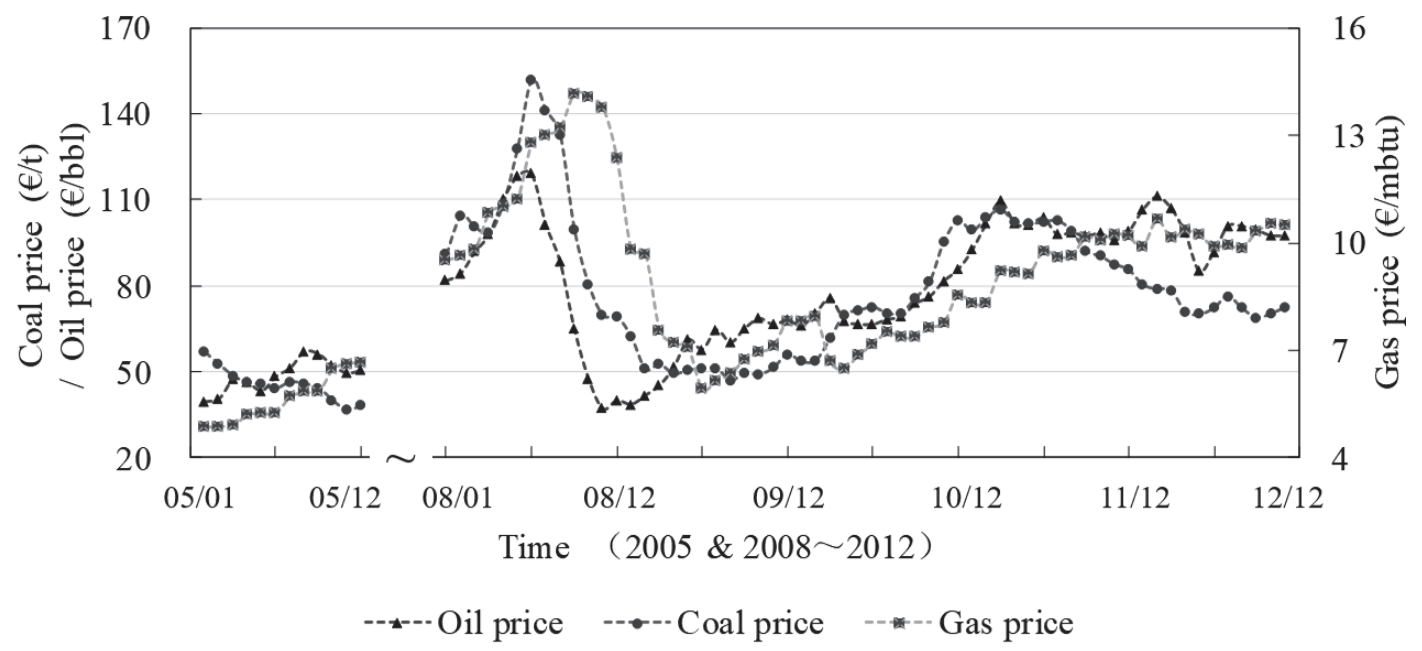

Fig. 5. Prices of fossil fuels in different years. 


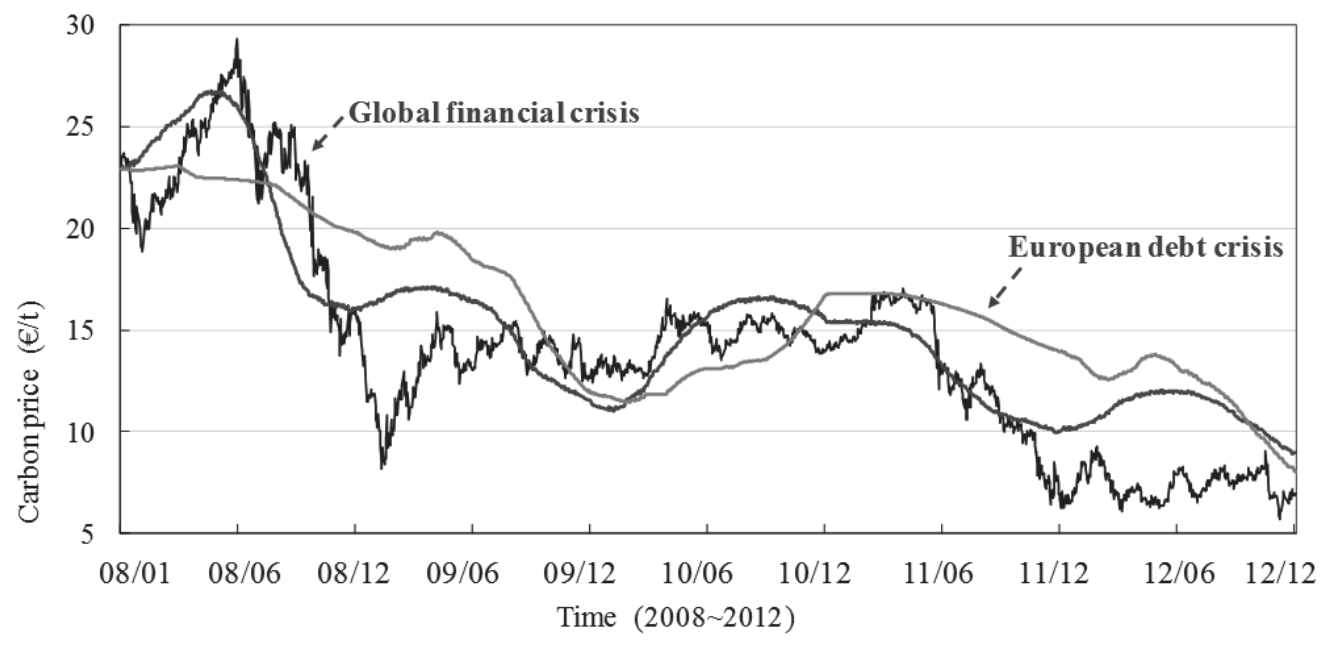

- Actual carbon price curve in EU ETS
- Carbon price curve obtained by the method in this paper
—Carbon price curve obtained by the method in Ref.[15]

Fig. 6. Comparison between the simulation results and the actual carbon price curve.

energy are constructed in Fig. 3 and Fig. 4. In terms of thermal power units, the ENTSO-E counts the total installed capacity of three types of thermal power units, including coal-fired units, gas-fired units and oil-fired units, and counts large-scale units of more than $400 \mathrm{MW}$, medium-scale units of between $200 \mathrm{MW}$ and $400 \mathrm{MW}$, and small-scale units of less than 200 MW. Based on this, each type of thermal power units is divided and the similar units are aggregated into a single unit. After the division, there are 9 types of thermal power units, and the corresponding installed capacity is shown in Table 2 and the corresponding energy consumption rate and emission rate are set according to the performance indicators of typical thermal power units in Table 3. The fossil fuel price curve comes from the World Bank website (as shown in Fig. 5).

\section{Market Disturbance}

The major disturbance in the actual operation of the EU ETS during the second phase came from the global financial crisis and the EU debt crisis. The impact of this disturbance on the European energy industry is reflected in a decline in energy demand and fluctuations in fossil fuel prices. In case study of this paper, the impact of macroeconomic disturbance on the carbon market is characterized by load fluctuations and fuel price fluctuations (as shown in Fig. 3 and Fig. 5).

\section{Results and Discussion}

\section{Model's Feasibility}

Based on the carbon market dynamic assessment model, the above parameters are used to simulate the carbon price in the EU ETS. The simulation results show that the price dynamics obtained by the simulation are close to the actual dynamics of the price (Pearson correlation coefficient is 0.88), reflecting the impact of the two major disturbances of the "global financial crisis" and the "European debt crisis" on the carbon market price, and furthermore it can describe the mechanism that the influences of economic disturbances are transmitted to the carbon market price gradually through power load, carbon emissions, participants' market position, trading behaviors, and the allowance supply and demand (as shown in Fig. 6). The carbon price curve obtained by the method in [15] is not obviously responsive to the two major disturbances, and its Pearson correlation coefficient is 0.77 .

Comparing the simulation results of these two methods, the method we proposed before obviously shows advantages in simulating carbon market dynamics, especially the response to the two major disturbances. As it is limited by the availability of market information, and the modeling of market mechanism and trading behavior is still crude, it is still difficult to simulate the details of carbon market fluctuations on a smaller time scale. However, in terms of the overall carbon price trend, the carbon market dynamic assessment model could be used as a reliable simulation tool for the sensitivity analysis of key factors influencing carbon prices under the EU ETS.

\section{Influences of Emission Reduction Targets on Carbon Prices}

\section{Scenario Settings}

EU ETS in 2011 was taken as the research object. The emission reduction targets are set to reduce 


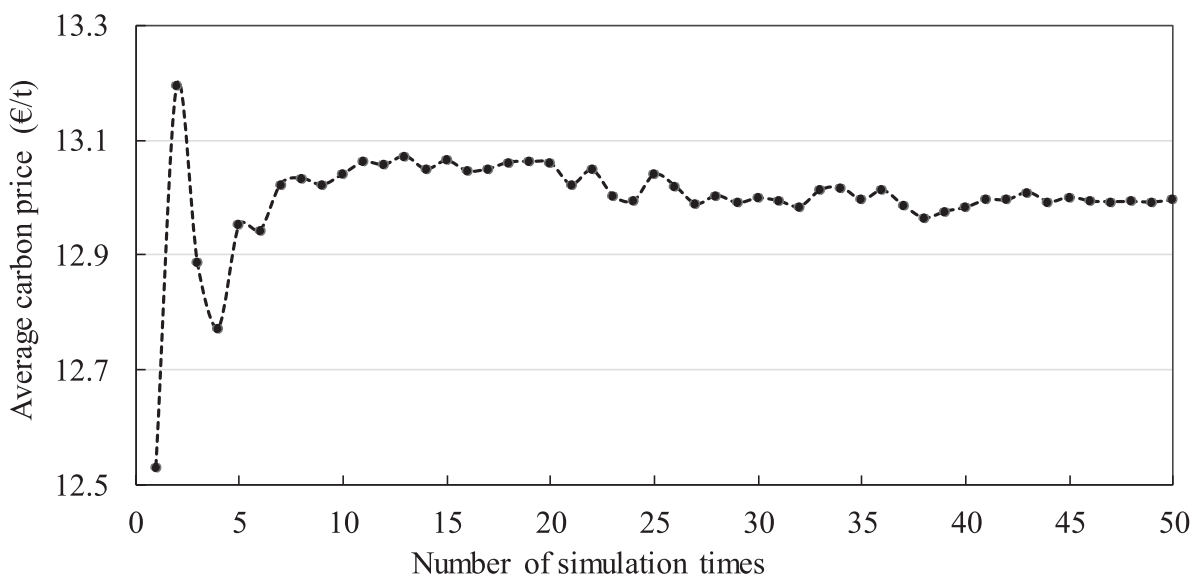

Fig. 7. Convergence of the carbon prices.

emission by $5 \%, 10 \%, 15 \%, 20 \%, 25 \%, 30 \%, 35 \%$, and $40 \%$, respectively, compared to the scenario without emission control.

\section{Convergence of Average Carbon Values}

It needs to be mentioned that as stochastic behavioral model is adopted in the case studies, simulation results under a given scenario are also stochastic. According to the "Law of Large Numbers", the statistical result will converge to a stable value after a sufficient number of repetitive simulations. Taking the 5\% emission reduction scenario as an example, after 50 times of repetitive simulations, the annual average carbon price converges to a relatively stable value (as shown in Fig. 7), which can represent the market status under this scenario, and we use "average carbon price" to denote this value.

\section{Clearing Order of Power Units}

Without considering the strategic quotation in this paper, GenCos use the marginal power generation cost as the quotation. Therefore, the marginal power generation cost determines the power units' clearing order. If the marginal emission cost introduced by carbon prices is not considered, the coal-fired units with the higher emission rates have the priority to output because of the lowest marginal power generation cost. With the increase of carbon prices, gas units with lower emission rates have advantages in marginal power generation cost. When the carbon price reaches to a certain threshold, the gas units have the priority to output compared to the coal-fired units (as shown in Fig. 8). For easy to describe, the carbon price that changes the units' clearing order is called the "threshold carbon price".

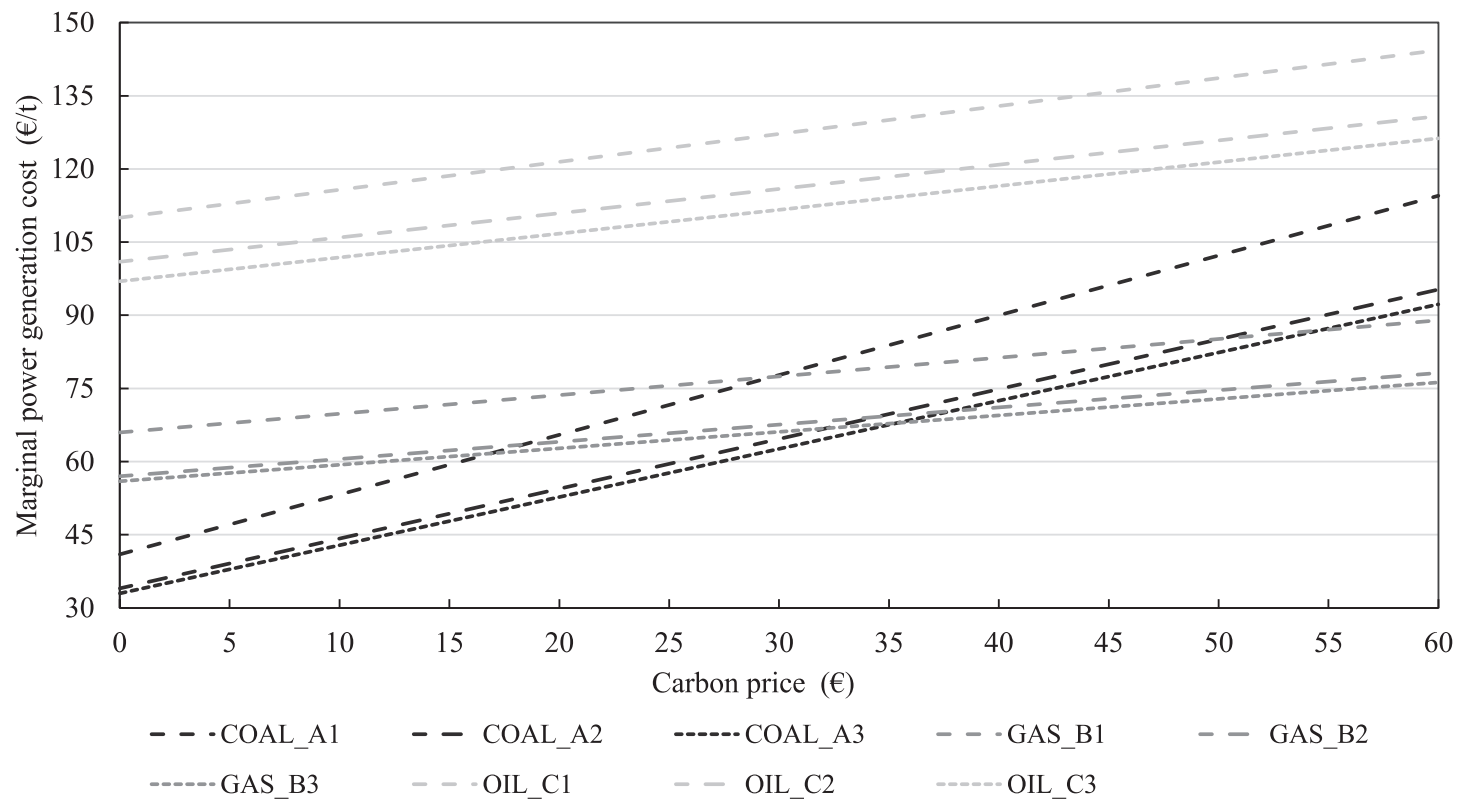

Fig. 8. Relation between marginal power generation cost and carbon prices. 


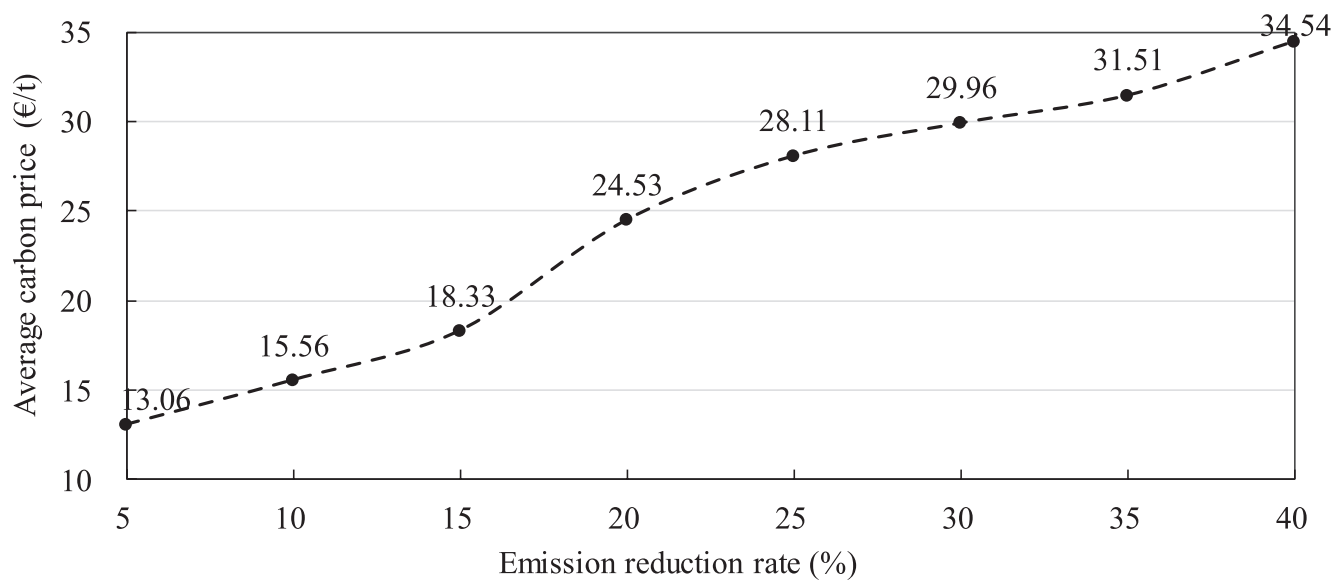

Fig. 9. Influences of emission reduction targets on carbon prices.

\section{Simulation Results and Discussion}

As the emission reduction target increases and the initial allocation of allowances decreases, the carbon price level will increase according to the demand-price model. The simulation results show that the average carbon price increases with the increase of emission reduction targets, but it is not proportionally increased (as shown in Fig. 9). When the emission reduction target is increased from $25 \%$ to $35 \%$, the carbon price curve values are already close to the threshold carbon price. Therefore, only a little more increase is needed to exceed the threshold carbon price, and the gas-fired units replace the coal-fired units to generate electricity so that the annual emissions are reduced to meet the emission reduction target. Therefore, the growth of the average carbon price in this period is slowing down.

The above results show under the same emission reduction ratio, the carbon price changes in different proportions, and in other words the efficiency of emission reduction is different. In particular, in some scenarios, carbon price incentives are not enough to change the order of GenCos, which is in line with the fact that carbon prices are relatively low compared with the social cost of carbon [30], so the market probably could only incur more costs rather than bring about corresponding emission reductions.

\section{Influences of Power Loads on Carbon Prices}

\section{Scenario Settings}

The baseline scenario is set with 5\% emission reduction target. On this basis, the power load increases by $5 \%, 10 \%$, and $15 \%$, and decreases by $5 \%, 10 \%$ and $15 \%$ respectively, compared to the baseline scenario.

\section{Simulation Results and Discussion}

When the emission reduction target is $5 \%$, if the load is lower than a certain level, the emission reduction is mainly caused by the reduction of the load level, rather than the increased output of the low-emission units. Therefore, when the load level is $85 \% \sim 95 \%$ compared with the load level of the baseline scenario,

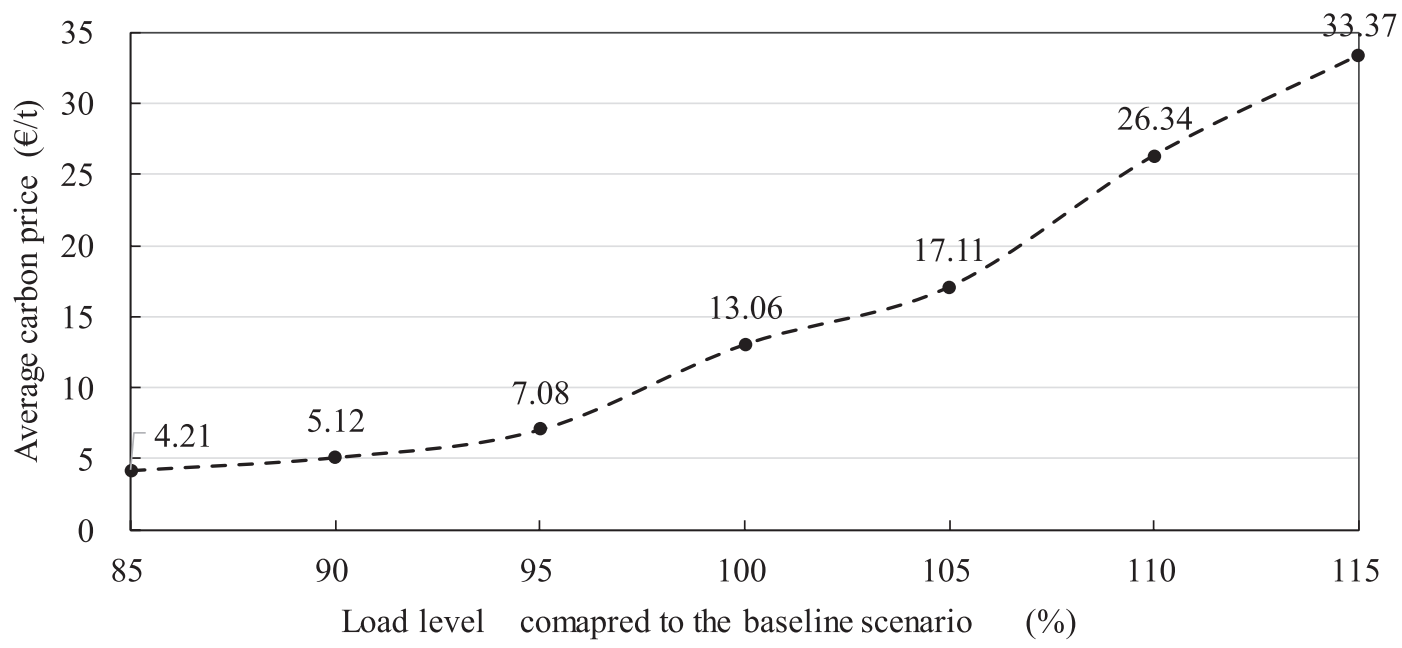

Fig. 10. Influences of power loads on carbon prices. 


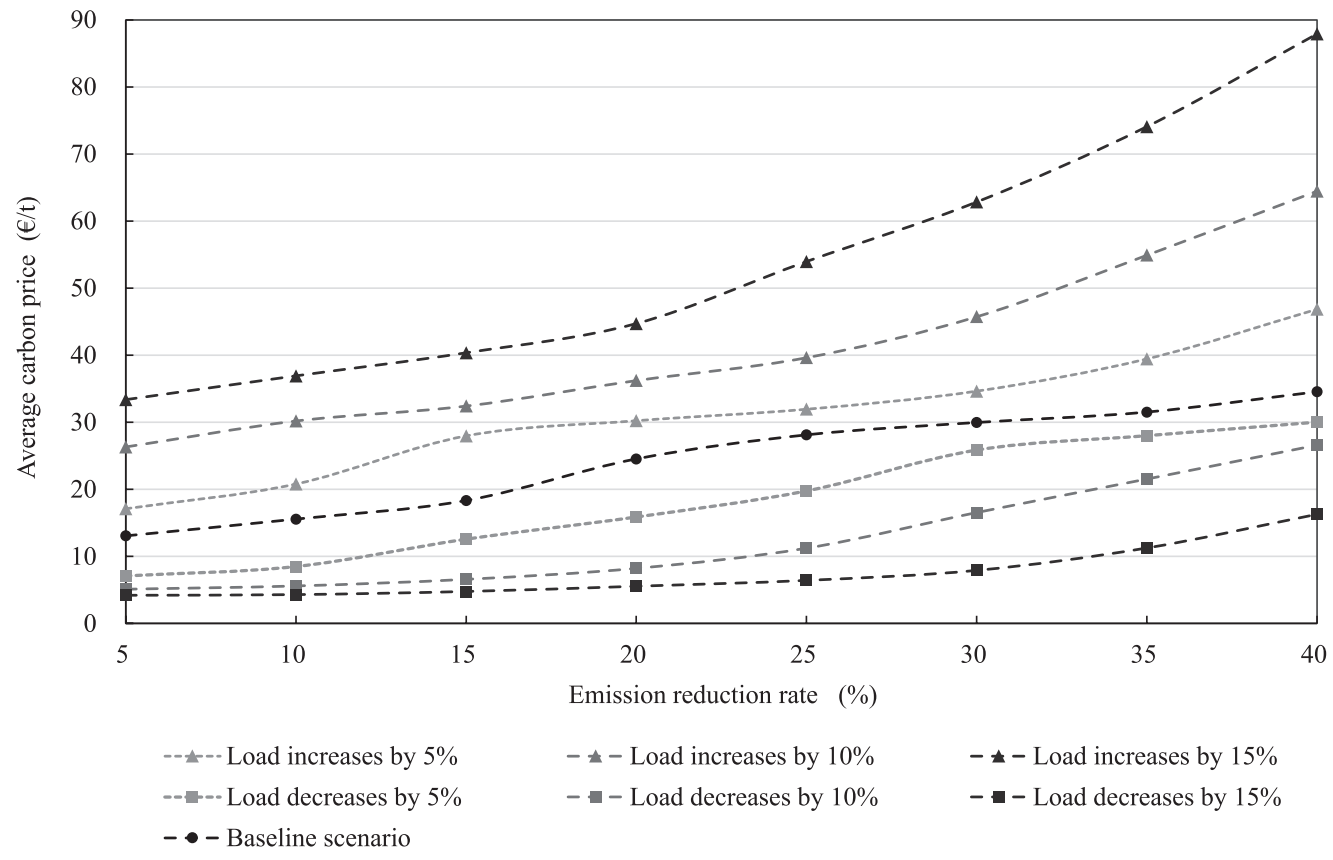

Fig. 11. Joint influences of power loads and emission reduction targets on carbon prices.

the average carbon price changes slowly. This result is consistent with the fact that the carbon prices of EU ETS remain low level despite the emission reduction target has been set [31], and the main reason is that energy consumption has dropped significantly due to the economic crisis. As the load level increases, the emission reduction is mainly caused by the increased output of the low-emission units. Therefore, when the load level is $105 \% \sim 115 \%$, the average carbon price changes rapidly (as shown in Fig. 10). Therefore, when facing with the influence of external factors, the regulators may need other measures to support the emission reduction target, such as a carbon price floor for ETS [32].

\section{Joint Influences of Power Loads and Emission Reduction Targets on Carbon Prices}

\section{Scenario Settings}

The emission reduction targets are set to reduce emission by $5 \%, 10 \%, 15 \%, 20 \%, 25 \%, 30 \%, 35 \%$, and $40 \%$, respectively, compared to the scenario without emission control. The power load increases by $5 \%$, $10 \%$, and $15 \%$, and decreases by $5 \%, 10 \%$ and $15 \%$ respectively compared to the baseline scenario.

\section{Simulation Results and Discussion}

It can be seen from the above discussions that the total emissions are more susceptible to changes of load parameters. When the load level is reduced by $15 \%$, the average carbon price is less impacted by the emission reduction target (as shown in Fig. 11), which explains the European Commission could do little to stabilize the carbon market when facing the disturbances of the global financial crisis and the European crisis, since the biggest share of emission reduction is due to the economic recession rather than to the EU ETS [33]. As the load level increases, the emission reduction target has more and more influence on the average carbon price.

Given the differences in the nature of these two parameters, the emission reduction target is the value set by the regulators, which will not change easily during the implementation period due to the legal basis [34]. The load level is a variable in the system, which is susceptible to the external environment such as primary energy, economic conditions, and climate change. For instance, the carbon emission reduction in EU ETS is mainly due to the reduction of production activities because of the global financial crisis. Therefore, it is necessary to consider the difference between the two parameters and the characteristics of the joint impact, in order to design a more efficient carbon market.

\section{Relation between Average Electricity Prices and Average Carbon Prices}

The power industry is the primary participator in the carbon market. The violent fluctuation of carbon prices not only affects the power generation cost of different primary energy sources and the operation of power systems on a short-time scale, but also affects the power supply structure on a long-time scale. In order to coordinate the efficient operation of the power system and emission reduction targets, it is necessary to analyze the transfer rate $\eta_{k}^{\text {trans }}$ from carbon prices to electricity prices, which is shown in the equation (7). 


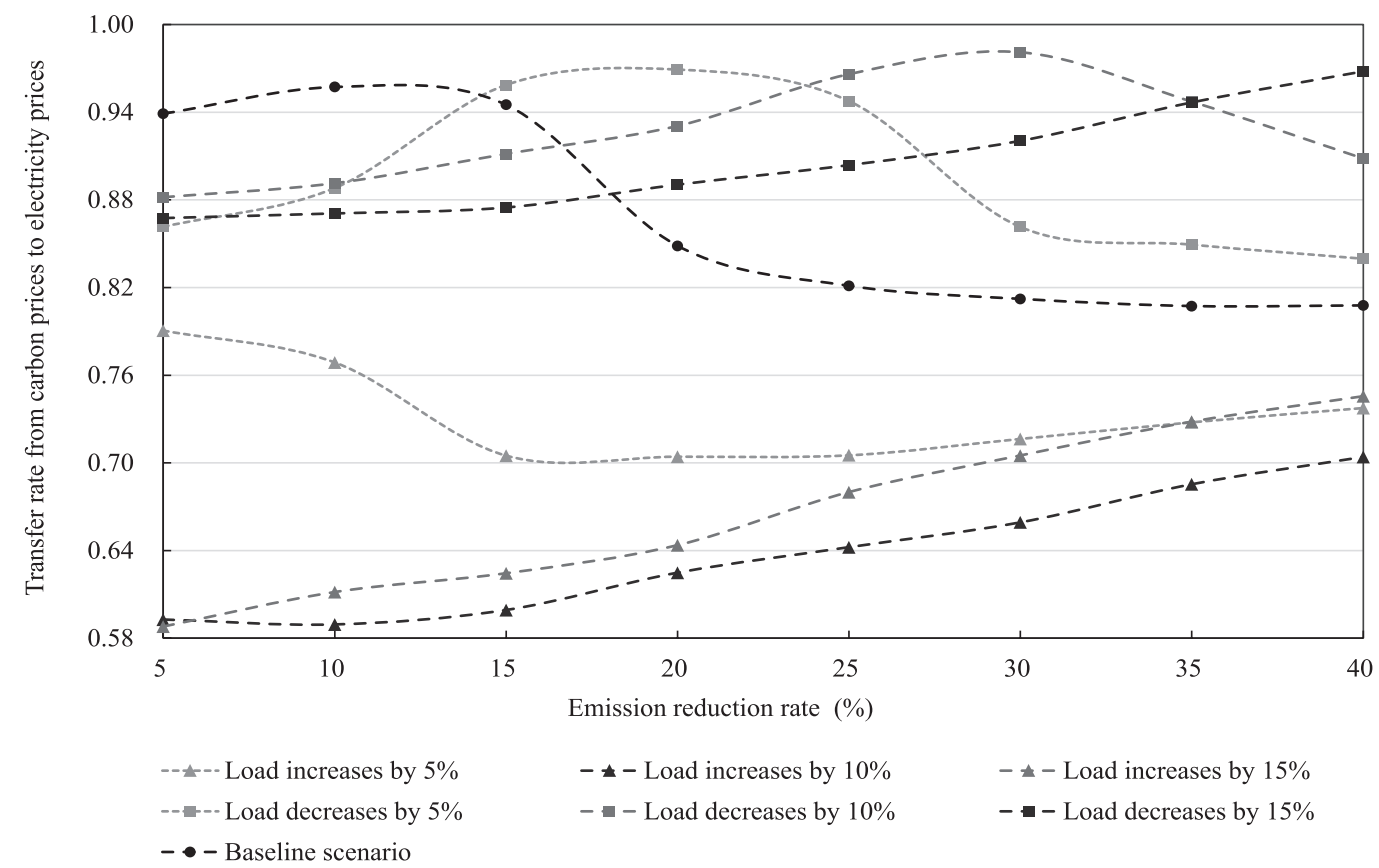

Fig. 12. Transfer rate from carbon prices to electricity prices.

$$
\eta_{k}^{\text {trans }}=\frac{p_{k}^{u a}-p_{w}^{u a}}{p_{k}^{e a}}
$$

Among them, $p_{k}^{u a}$ is the average electricity price under the emission reduction scenario $k, p_{w}^{\text {ua }}$ is the average electricity price without the emission regulation, and $p_{k}^{e a}$ is the average carbon price under the emission reduction scenario $k$.

When the carbon price is getting higher to reach the threshold carbon price, the low-emission units will be cleared preferentially. Therefore, the electricity price is determined by the unit with higher emission rate. However, as the carbon price increases, but does not reach the threshold carbon price, the corresponding electricity price will not change because of the unchanged clearing order of units, the transfer rate will decrease though (as shown in Fig. 12). Therefore, when studying the impact of the carbon market on the electricity market, it is necessary to complete the sensitivity analysis of relevant parameters instead of the single parameter analysis.

It is clear from the above results that not all carbon prices are transmitted to the electricity prices, which is consistent with some empirical studies [35]. It is possible to suppose that GenCos' profits would be affected, due to the transition of allocation rules from grandfathering to auctioning for the electricity sector. With earnings from auctioning, regulators need to consider the transfer rate from carbon prices to electricity prices, to decide whether to support GenCos financially to ensure the stability of the power grid in the short term.

It should be noted that under the benchmark electricity price system in some countries, such as
China, the determination of the on-grid price is not affected by the carbon price. The non-conductivity of carbon cost will have a greater impact on the total profit of GenCos. At present, China's electricity price mechanism is mainly according to the government's benchmarking price, which is mainly based on the economic life cycle of power generation projects, and the principle of reasonable compensation costs. Carbon cost is not used as a reference for benchmarking electricity prices. Once carbon cost is high enough, GenCos will fall into a loss situation. Since the marginal revenue is negative, the power generation will lead to greater losses, which will cause GenCos to lose their enthusiasm for power generation. Some GenCos may even reduce power generation through maintenance, resulting in power shortage. This result may be inconsistent with many studies and surveys that GenCos prefer a high carbon price [36], and the reason lies in different electricity price systems. Consequently, under the regulated electricity price regime, some governmental subsidies should be needed to support electricity production as a good starting point for the introduction of ETS [37].

\section{Conclusions}

This paper constructs a carbon market dynamic assessment model that considers the behavior of market participants, according to the rules and specific data of EU ETS. Furthermore, the feasibility of the model is verified by simulating the carbon price crisis of the second stage of EU ETS, providing an effective simulation tool to support regulators to design and improve the carbon market. 
Based on this model, the sensitivity analysis of key factors in EU ETS is conducted to enhance understanding on the dynamic operation of the carbon market. The most intriguing finding of this paper is that when the carbon price is close to the threshold carbon price, only a little more increase is needed to exceed the threshold carbon price that can change the power units' clearing order. That means less cost could achieve the same emission reduction, which is of great importance for regulators to improve the market efficiency. Besides, the total emissions are more susceptible to changes of load parameters in contrast to the emission reduction target. That explains the European Commission could do little to stabilize the carbon market when facing the disturbances of the global financial crisis and the European crisis.

This paper also provides an analysis on the relation between average electricity and average carbon prices. The threshold carbon price also has a great important influence on the transfer rate from carbon prices to electricity prices, further affecting the social welfare. It should be noted in some countries, such as China, the electricity market is under the benchmark electricity price system, which means the on-grid price is not affected by the carbon price. The non-conductivity of carbon cost may reduce GenCos' power generation, resulting in power shortage.
As a preliminary exploration research, it is limited by the availability of market information, and the modeling of market mechanism and trading behavior is still crude, but the simulation results fully show that the carbon market dynamic assessment model can simulate the long-term trend of the carbon price and the sensitivity analysis provides some interesting insights for regulators to better understand the dynamic operation of the carbon market.

\section{Acknowledgments}

This work is supported by the Universities Natural Science Research Project of Jiangsu Province, China (Grant No.19KJB120015) and the Natural Science Foundation of Jiangsu Province, China (Grant No. BK20190878).

\section{Conflicts of Interests}

The authors declare no conflict of interest.

\section{Appendix A}

Table A1. Trading probabilities of behavioral agents when $r_{t}^{f}>5 \%$.

\begin{tabular}{|c|c|c|c|c|c|c|}
\hline \multirow{2}{*}{$r_{t}^{p}(\%)$} & \multicolumn{7}{|c|}{ Trading probabilities corresponding to $r_{t}^{u}(\%)$} \\
\cline { 2 - 7 } & $(-\infty,-16]$ & $(-16,-14]$ & $(-14,-12]$ & $(-12,-10]$ & $(-10,-8]$ & $(-8,+\infty)$ \\
\hline$(-\infty,-20]$ & 0.76 & 0.55 & 0.28 & 0.21 & 0.04 & 0 \\
\hline$(-20,-10]$ & 0.46 & 0.34 & 0.22 & 0.15 & 0.02 & 0 \\
\hline$(-10,0]$ & 0.32 & 0.26 & 0.15 & 0.05 & 0.02 & 0 \\
\hline$(0,10]$ & 0 & 0 & 0.01 & 0.04 & 0.09 & 0.12 \\
\hline$(10,20]$ & 0 & 0 & 0.06 & 0.11 & 0.27 & 0.42 \\
\hline$(20,+\infty)$ & 0.01 & 0.05 & 0.09 & 0.26 & 0.31 & 0.53 \\
\hline
\end{tabular}

Table A2. Trading probabilities of behavioral agents when $-5 \% \leq r_{t}^{f \leq 5 \%}$.

\begin{tabular}{|c|c|c|c|c|c|c|}
\hline \multirow{2}{*}{$r_{t}^{p}(\%)$} & \multicolumn{7}{|c|}{ Trading probabilities corresponding to $r_{t}^{u}(\%)$} \\
\cline { 2 - 7 } & $(-\infty,-16]$ & $(-16,-14]$ & $(-14,-12]$ & $(-12,-10]$ & $(-10,-8]$ & $(-8,+\infty)$ \\
\hline$(-\infty,-20]$ & 0.64 & 0.34 & 0.21 & 0.11 & 0.05 & 0.00 \\
\hline$(-20,-10]$ & 0.33 & 0.25 & 0.15 & 0.12 & 0.02 & 0.00 \\
\hline$(-10,0]$ & 0.28 & 0.21 & 0.14 & 0.08 & 0.02 & 0.00 \\
\hline$(0,10]$ & 0.00 & 0.00 & 0.02 & 0.04 & 0.12 & 0.14 \\
\hline$(10,20]$ & 0.00 & 0.00 & 0.06 & 0.18 & 0.29 & 0.35 \\
\hline$(20,+\infty)$ & 0.01 & 0.05 & 0.07 & 0.30 & 0.40 & 0.60 \\
\hline
\end{tabular}




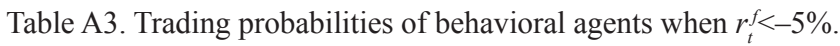

\begin{tabular}{|c|c|c|c|c|c|c|}
\hline \multirow{2}{*}{$r_{t}^{p}(\%)$} & \multicolumn{7}{|c|}{ Trading probabilities corresponding to $r_{t}^{u}(\%)$} \\
\cline { 2 - 7 } & $(-\infty,-16]$ & $(-16,-14]$ & $(-14,-12]$ & $(-12,-10]$ & $(-10,-8]$ & $(-8,+\infty)$ \\
\hline$(-\infty,-20]$ & 0.49 & 0.28 & 0.13 & 0.08 & 0.01 & 0.00 \\
\hline$(-20,-10]$ & 0.29 & 0.18 & 0.11 & 0.07 & 0.02 & 0.00 \\
\hline$(-10,0]$ & 0.22 & 0.18 & 0.14 & 0.08 & 0.02 & 0.00 \\
\hline$(0,10]$ & 0.00 & 0.00 & 0.03 & 0.04 & 0.18 & 0.22 \\
\hline$(10,20]$ & 0.00 & 0.00 & 0.13 & 0.29 & 0.34 & 0.47 \\
\hline$(20,+\infty)$ & 0.02 & 0.05 & 0.24 & 0.35 & 0.49 & 0.71 \\
\hline
\end{tabular}

Table A4. Average trading volume of behavioral agents when $r_{t}^{f}>5 \%$.

\begin{tabular}{|c|c|c|c|c|c|c|}
\hline \multirow{2}{*}{$r_{t}^{p}(\%)$} & \multicolumn{5}{|c|}{ Ratio $\left(\times 10^{-2}\right)$ of average trading volume to initial allowance allocation corresponding to $r_{t}^{u}(\%)$} \\
\cline { 2 - 7 } & $(-\infty,-16]$ & $(-16,-14]$ & $(-14,-12]$ & $(-12,-10]$ & $(-10,-8]$ & $(-8,+\infty)$ \\
\hline$(-\infty,-20]$ & 1.75 & 1.55 & 1.41 & 0.72 & 0.50 & 0 \\
\hline$(-20,-10]$ & 1.47 & 1.30 & 0.96 & 0.38 & 0.29 & 0 \\
\hline$(-10,0]$ & 1.00 & 0.87 & 0.68 & 0.18 & 0.11 & 0 \\
\hline$(0,10]$ & 0 & 0 & -0.06 & -0.09 & -0.22 & -0.41 \\
\hline$(10,20]$ & 0 & 0 & -0.06 & -0.13 & -0.36 & -0.60 \\
\hline$(20,+\infty)$ & -0.07 & -0.13 & -0.27 & -0.44 & -0.79 & -0.94 \\
\hline
\end{tabular}

Table A5. Average trading volume of behavioral agents when $-5 \% \leq r_{t}^{f} \leq 5 \%$.

\begin{tabular}{|c|c|c|c|c|c|c|}
\hline \multirow{2}{*}{$r_{t}^{p}(\%)$} & \multicolumn{5}{|c|}{ Ratio $\left(\times 10^{-2}\right)$ of average trading volume to initial allowance allocation corresponding to $r_{t}^{u}(\%)$} \\
\cline { 2 - 7 } & $(-\infty,-16]$ & $(-16,-14]$ & $(-14,-12]$ & $(-12,-10]$ & $(-10,-8]$ & $(-8,+\infty)$ \\
\hline$(-\infty,-20]$ & 1.65 & 1.28 & 1.09 & 0.61 & 0.34 & 0 \\
\hline$(-20,-10]$ & 1.14 & 0.92 & 0.51 & 0.33 & 0.17 & 0 \\
\hline$(-10,0]$ & 0.83 & 0.55 & 0.39 & 0.14 & 0.08 & 0 \\
\hline$(0,10]$ & 0 & 0 & -0.06 & -0.13 & -0.32 & -0.51 \\
\hline$(10,20]$ & 0 & 0 & -0.06 & -0.17 & -0.41 & -0.71 \\
\hline$(20,+\infty)$ & -0.07 & -0.14 & -0.35 & -0.59 & -0.98 & -1.14 \\
\hline
\end{tabular}

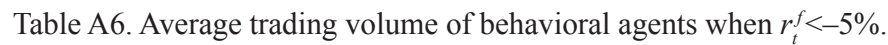

\begin{tabular}{|c|c|c|c|c|c|c|}
\hline \multirow{2}{*}{$r_{t}^{p}(\%)$} & \multicolumn{5}{|c|}{ Ratio $\left(\times 10^{-2}\right)$ of average trading volume to initial allowance allocation corresponding to ${ }_{t}^{u}(\%)$} \\
\cline { 2 - 7 } & $(-\infty,-16]$ & $(-16,-14]$ & $(-14,-12]$ & $(-12,-10]$ & $(-10,-8]$ & $(-8,+\infty)$ \\
\hline$(-\infty,-20]$ & 1.49 & 1.02 & 0.68 & 0.45 & 0.30 & 0 \\
\hline$(-20,-10]$ & 0.93 & 0.76 & 0.42 & 0.22 & 0.13 & 0 \\
\hline$(-10,0]$ & 0.68 & 0.45 & 0.32 & 0.13 & 0.07 & 0 \\
\hline$(0,10]$ & 0 & 0 & -0.06 & -0.20 & -0.37 & -0.61 \\
\hline$(10,20]$ & 0 & 0 & -0.09 & -0.24 & -0.49 & -0.90 \\
\hline$(20,+\infty)$ & -0.13 & -0.20 & -0.44 & -0.86 & -1.13 & -1.33 \\
\hline
\end{tabular}




\section{References}

1. SHISHLOV I., MOREL R., BELLASSEN V. Compliance of the Parties to the Kyoto Protocol in the first commitment period. Clim. Policy, 16 (6), 768, 2016.

2. KNOLL L. Sustainable Markets and the State: Taxation, Cap-and-Trade, Pay-for-Success, and Nudging. Hist. Soc. Res., 44 (1), 231, 2019.

3. KOSNIK L.R. Cap-and-trade versus carbon taxes: which market mechanism gets the most attention? Climatic Change, 151 (3-4), 605, 2018.

4. KEOHANE N., PETSONK, A., HANAFI A. Toward a club of carbon markets. Climatic Change, 144 (1), 81, 2017.

5. WARA M. Is the global carbon market working? Nature, 445 (7128), 595, 2007.

6. HINTERMANN B., PETERSON S., RICKELS W. Price and Market Behavior in Phase II of the EU ETS: A Review of the Literature. Rev. Env. Econ. Policy, 10 (1), 108, 2016.

7. SONG Y.Z., LIU T.S., LIANG D.P., LI Y., SONG X.Q. A Fuzzy Stochastic Model for Carbon Price Prediction Under the Effect of Demand-related Policy in China's Carbon Market. Ecol. Econ., 157, 253, 2019.

8. BYUN S.J., CHO H. Forecasting carbon futures volatility using GARCH models with energy volatilities. Energ. Econ., 40, 207, 2013.

9. MU Y.Q., EVANS S., WANG C., CAI W.J. How will sectoral coverage affect the efficiency of an emissions trading system? A CGE-based case study of China. Appl. Energ., 227, 403, 2018.

10. THURBER M.C., DAVIS T.L., WOLAK F.A. Simulating the interaction of a renewable portfolio standard with electricity and carbon markets. Electricity Journal, 28 (4), 51, 2015.

11. THURBER M.C., WOLAK F.A. Carbon in the classroom: lessons from a simulation of California's electricity market under a stringent cap-and-trade system. The Electricity Journal, 26 (7), 8, 2013.

12. JIANG W., LIU J., LIU X. Impact of Carbon Quota Allocation Mechanism on Emissions Trading: An Agent-Based Simulation. Sustainability-Basel, 8 (8), 826, 2016.

13. ZHANG H., CAO L.B., ZHANG, B. Emissions trading and technology adoption: An adaptive agent-based analysis of thermal power plants in China. Resour. Conserv. Recy., 121, 23, 2017.

14. TANG L., WU J.Q., YU L., BAO Q. Carbon allowance auction design of China's emissions trading scheme: A multi-agent-based approach. Energ. Policy, 102, 30, 2017.

15. DONG-BIN H., CAI-FENG L., HONG-PENG C. Carbon Emission Market Modeling and Simulation Based on Complex Adaptive System Theory. The Open Cybernetics \& Systemics Journal, 8 (1), 1175, 2014.

16. DONG F., DAI Y., ZHANG S.N., ZHANG X.Y., LONG R.Y. Can a carbon emission trading scheme generate the Porter effect? Evidence from pilot areas in China. Sci. Total Environ., 653, 565, 2019.

17. DONG F., LI J.Y., WANG Y., ZHANG X.Y., ZHANG S.N., ZHANG S.Q. Drivers of the decoupling indicator between the economic growth and energy-related $\mathrm{CO}_{2}$ in China: A revisit from the perspectives of decomposition and spatiotemporal heterogeneity. Sci. Total Environ., 685, 631, 2019.
18. DONG F., YU B.L., PAN Y.L. Examining the synergistic effect of $\mathrm{CO}_{2}$ emissions on $\mathrm{PM}_{2.5}$ emissions reduction: Evidence from China. J. Clean. Prod., 223, 759, 2019.

19. VERDE S.F., GRAF C., JONG T. Installation entries and exits in the EU ETS: patterns and the delay effect of closure provisions. Energ. Econ., 78, 508, 2019.

20. BALIETTI A.C. Trader types and volatility of emission allowance prices. Evidence from EU ETS Phase I. Energ. Policy, 98, 607, 2016.

21. FAN Y., JIA J.J., WANG X., XU J.H. What policy adjustments in the EU ETS truly affected the carbon prices? Energ. Policy, 103, 145, 2017.

22. YANG L., LIN B. Carbon dioxide-emission in China' $\mathrm{s}$ power industry: evidence and policy implications. Renewable and Sustainable Energy Reviews, 60, 258, 2016.

23. HEALY S., GRAICHEN V., GORES S. Trends and projections in the EU ETS in 2016: The EU emissions trading system in numbers. Publications Office of the European Union, 2016.

24. BERGHMANS N., CHÈZE B., ALBEROLA E., CHEVALLIER J. The $\mathrm{CO}_{2}$ emissions of the European power sector: economic drivers and the climate-energy policies 'contribution'. In CDC Climate Research Working Paper No. 2014-17, 2014.

25. HEINDL P., LUTZ B.J. Carbon Management-Evidence from Case Studies of German Firms under the EU ETS. ZEW-Centre for European Economic Research Discussion Paper, 12, 2012.

26. BENZ E., LÖSCHEL A., STURM B. Auctioning of $\mathrm{CO}_{2}$ emission allowances in Phase 3 of the EU Emissions Trading Scheme. Clim. Policy, 10 (6), 705, 2010.

27. XUE Y., JIANG C., HUANG J., WEN F., DING Y., XU Z., WONG K. In A hybrid interactive simulation method for studying emission trading behaviors, 2015 IEEE Power \& Energy Society General Meeting (pp. 1-5), IEEE, 2015.

28. JIANG C., XUE Y., HUANG J., XUE F., WEN F., LI K. Aggregated impact of allowance allocation and power dispatching on emission reduction. Journal of Modern Power Systems and Clean Energy, 5 (6), 936, 2017.

29. JIANG C., XUE Y., HUANG J., WU Q., YANG G. Modeling multi-agent in carbon emission market based on experimental economics simulations. Automation of Electric Power Systems, 38 (17), 80, 2014.

30. BRINK C., VOLLEBERGH H.R.J., WERF E.V.D. Carbon pricing in the EU: Evaluation of different EU ETS reform options. Energ. Policy, 97, 603, 2016.

31. KOCH N., FUSS S., GROSJEAN G., EDENHOFER O. Causes of the EU ETS price drop: Recession, CDM, renewable policies or a bit of everything? - New evidence. Energ. Policy, 73, 676, 2014.

32. BRAUNEIS A., MESTEL R., PALAN S. Inducing lowcarbon investment in the electric power industry through a price floor for emissions trading. Energ. Policy, 53, 190, 2013.

33. BEL G., JOSEPH S. Emission abatement: Untangling the impacts of the EU ETS and the economic crisis. Energ. Econ., 49, 531, 2015.

34. ZHANG Y.J., WEI Y.M. An overview of current research on EU ETS: Evidence from its operating mechanism and economic effect. Appl. Energ., 87 (6), 1804, 2010.

35. FREITAS C.J.P., SILVA P.P.D. European Union emissions trading scheme impact on the Spanish electricity price during phase II and phase III implementation. Util. Policy, 33, 54, 2015. 
36. XENOPHON A.K., HILL D.J. Emissions reduction and wholesale electricity price targeting using an output-based mechanism. Appl. Energ., 242, 1050, 2019.
37. LI J.F., WANG X., ZHANG Y.X., KOU Q. The economic impact of carbon pricing with regulated electricity prices in China - An application of a computable general equilibrium approach. Energ. Policy, 75, 46, 2014. 